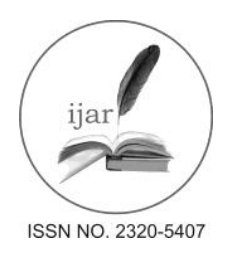

\section{Journal homepage:http://www.journalijar.com \\ Journal DOI:10.21474/IJAR01}

RESEARCH ARTICLE
INTERNATIONAL JOURNAL

OF ADVANCED RESEARCH

(1)

\title{
HISTOLOGICAL AND IMMUNOHISTOCHEMICAL IMPLICATIONS OF KETAMINE PROTRACTED DOSES AS A NOVEL CANDIDATE IN ANTIDEPRESSANT TREATMENTON ADULT RAT CEREBELLAR CORTEX.
}

\author{
Samar A. Asker ${ }^{1}$, Shireen A. Mazroa ${ }^{1}$, Youmna Sabri ${ }^{2}$ \\ 1. Histology \& Cell Biology Department, Faculty of Medicine, Mansoura University, Egypt. \\ 2. Department of Psychiatry; Faculty of Medicine; Mansoura University; Mansoura, Egypt.
}

\section{Manuscript Info Abstract}

Manuscript History:

Received: 28 April 2016

Final Accepted: 11 May 2016

Published Online: June 2016

Key words:

Antidepressants, calretinin, cerebellum, GFAP,

immunohistochemistry, Ketamine,

Purkinje cells.

*Corresponding Author

Samar A. Asker.
Background:- Ketamine is commonly used as a dissociative anesthetic drug. However, some clinical studies suggested that ketamine ameliorated depressive symptoms in patients with major depression. Therefore, this study aimed to investigate histological and immunohistochemical implications of variable doses of ketamine administration on adult rat cerebellar cortex.

Material/Methods:- Thirty adult rats were divided into; group I (control), group II received IP injection of $5 \mathrm{mg} / \mathrm{kg}$ ketamine / 12 hours, and group III received IP injection of $20 \mathrm{mg} / \mathrm{kg}$ ketamine / 12 hours. After 14 days, cerebella were taken and prepared for histological study and immunohistochemical study for glial fibrillary acidic protein (GFAP) as a biomarker of neurotoxicity and for calretinin that plays an important role in the regulatory processes of calcium and has an anti-apoptotic cellular protective action.

Results:- Compared to group I, group II showed minimal degenerative changes. Purkinje cell layer showed a significant decrease in GFAP immunereaction and a significant increase in calretinin immune- reaction. Molecular and granular layers showed insignificant increase in GFAP immune- reaction and insignificant decrease in calretinin immune- reaction. Group III showed massive degenerative changes in the cerebellar cortex in addition to a significant decreased in GFAP and a significant increase in calretinin immune-reaction in Purkinje cell layer. Molecular and granular layers showed a significant increase in GFAP and a significant decrease in calretinin immune- reaction.

Conclusion:- repeated administration of ketamine induced dose dependent structural and immunohistochemical alterations in the cerebellar cortex, suggesting that the use of small doses is much safer.

Copy Right,IJAR, 2016. All rights reserved.

\section{Introduction:-}

Ketamine is a noncompetitive antagonist of the N-methyl-D-aspartate (NMDA) receptors, which is an important mediator of excitatory synaptic transmission and high permeability to calcium (Valiullina et al., 2016). Ketamine non-competitively binds to the phencyclidine site inside the NMDA receptor and blocks the influx of calcium (Dong and Anand 2013). Ketamine is commonly used as a dissociative anesthetic, presently included in the category of the psychoactive substances known as "club drugs" (Venâncioet al., 2011). Some clinical studies suggested that administration of ketamine ameliorated depressive symptoms in patients suffering from major depression (Niciu et 
al., 2013; Priceet al., 2014). Furthermore, evidence of successful repeated ketamine therapy reported an overall response for treatment of resistant patients of depression (Murroughet al., 2013).Theadministration ofdoses ranging from 0.5 - $20 \mathrm{mg} / \mathrm{Kg}$ was provedto be effective as antidepressantsin rats (Pariseet al., 2013; Tizabiet al., 2013). Some studies reported a neuroprotective effect of ketamine (Horvathet al., 2007; Labombarda et al., 2008). However, others demonstrated the possibility ofpostanesthetic psychotomimetic effects (Sos et al., 2013) and neurotoxicity through triggering neuroapoptosis in the developing brain (Young et al., 2005; Ito et al., 2015). There are conflicting data in the literatures concerning the most effective dose of ketamine to be used as an anti-depressant (Venâncio et al., 2011; Tizabiet al., 2013; Ito et al., 2015). Yet, the effect of varying doses of ketamine on the structure of the nervous tissue is in need of investigation.

The cerebellum is primarily considered as a center of motor coordination, although there is sufficient evidence showing that it is also involved in a number of cognitive tasks, such as the language processing (Hart , 2011). The cerebellum constitutes an ideal platform to study neural circuits in many respects. Many laboratories have used the cerebellar cortex as a template to understand the nervous system because of its well-defined network connectivity and relatively few types of cells involved (Ordek et al., 2013). Glial fibillirary acidic protein (GFAP) is a neurofilament, which belong to the family of intermediate filaments known to be specifically expressed in astrocytes (Sawantet al., 1994 ,Sriram et al., 2004). Its increase has been used as a biomarker of neurotoxicity (Callaghanand Sriram, 2005).

Calretinin (CR) is a protein that plays an important role in the regulatory processes of calcium and has an antiapoptotic cellular protective action (Szalak et al., 2015). Calretinin immunoreaction is expressed in certain cerebellar cells and fibers as unipolar brush cells, mossy fibers and climbing fibers (Alvarezet al., 2008). There is no doubt that calcium -binding proteins contribute to shaping presynaptic and postsynaptic signaling (Edmondset al., 2000). Regulation of calcium homeostasis may be a key in the protection of the brain from injury (Turneret al., 2009).

Therefore, the aim of the present study was to investigate the impact of protracted variable doses of ketamine administration on the histological structure and immunohistochemical expression of GFAP and calretinin in the adult rat cerebellar cortex.

\section{Materials and Methods:-}

All procedures in the study were performed in accordance with the institutional research board (IRB) committee in our institute. Thirty adult male albino rats (100-120 days old and 200-250 g weight) were housed 2 per cage with water and food ad libidum. Animals were equally randomized into three groups (10 rats / group). Group I included control rats that received intra-peritoneal (IP) injection of $1 \mathrm{ml}$ of $0.9 \%$ normal saline every 12 hours for 14 consecutive days. Group II included rats receiving $5 \mathrm{mg} / \mathrm{kg}$ IP injection of ketamine (Sigma, St Louis, MO, USA) every 12 hours for 14 consecutive days. Ketamine was obtained in an injectable solution form (100 mg/ ml) that was diluted in $0.9 \%$ normal saline. Group III included rats receiving IP injection of $20 \mathrm{mg} / \mathrm{kg}$ of ketamine for the same duration as the previous group. The selected doses were shown to be antidepressant in adult rats (Parise et al., 2013).

\section{Obtaining the samples:-}

Twenty-four hours after the final injection, the rats were deeply anesthetized with sodium pentobarbital $(60 \mathrm{mg} / \mathrm{kg}$, IP) (Akscynet al., 2016) and perfused with 9\% $\mathrm{NaCl}$ in $1 \mathrm{M}$ phosphate buffer (PBS: $\mathrm{pH} 7.4$ ), followed by neutral buffered formalin in $1 \mathrm{M}$ phosphate buffer $(\mathrm{pH} 7.4)$ through the left cardiac ventricle and ascending aorta. Cerebella were taken and cut section then immersed in $10 \%$ neutral buffered formalin overnight at a temperature of $4{ }^{\circ} \mathrm{C}$.

\section{Preparation of tissue samples:-}

Samples were dehydrated in alcohols, cleared in xylol and embedded in paraplast. Serial tissue sections of 5um thickness were stained with: haematoxylin and eosin (H\&E) to study the structural light microscopic changes, and toluidine blue to demonstrate Nissl granules (Suvarnaet al., 2013). Sections of 4 um thickness were used for the immunohistochemical localization of Glial Fibrillary Acidic Protein (GFAP) as a biomarker of neurotoxicity (Callaghan and Sriram , 2005) and calretinin $(C R)$, that plays an important role in the regulatory processes of calcium and has an anti-apoptotic cellular protective action (Gallet al., 2003) .

\section{Immunohistochemical (IHC) localization of GFAP and calretinin:-}


Kits used: Ready to use target retrieval solution (S1700, Dakocytomation, Glostrup, Denmark), a rabbit polyclonal primary antibody specific for antiglialfibrillary acidic protein (anti-GFAP) Z 0334 (Dakocytomation), Monoclonal Mouse Anti-Human Calretinin(Code No.: IS627,Dakocytomation) and ready to use antibody diluent with background reducing components (S3022, Dakocytomation). Universal detection kits (K 0673, Dakocytomation) based on a modified avidin-biotin (LAB).

\section{Steps of immune-staining:-}

Sections were dewaxed in xylol for 20 minutes, and hydrated in descending grades of alcohol down to distilled water. They were immersed into preheated target retrieval solution to $95-99^{\circ} \mathrm{C}$. Sections were rinsed 3 times with phosphate buffered saline (PBS). Excess liquid was tapped off the slides. Enough hydrogen peroxide was applied to cover the specimen for 5 minutes, then slides were rinsed gently with PBS and excess liquid was tapped off. Enough amount of primary antibody (dilution for GFAP is 1: 500 and for Calretinin 1: 50 according to manufacturer company)was applied on specimens, and was incubated for two hours in humidity chamber at room temperature. Slides were rinsed in PBS. Biotinylated link was applied on specimens for 10 minutes and sections were rinsed in PBS. Streptavidin HRP reagent was applied on specimens for 10 minutes and sections were then rinsed in PBS. Freshly prepared DAB substrate chromogen solution (1 drop of DAB chromogen /1 ml of substrate buffer) was applied on specimens for 10 minutes. Slides were rinsed gently in distilled water, immersed in haematoxylin for $1 / 2$ minute and were rinsed in tap water until blue. Slides were dehydrated in ascending grades of alcohol, cleared in xylol, mounted by Canada balsam and covered with a cover slip.Human cerebral cortex and testis (obtained from the pathology department in our institution) served as a positive control for GFAP(Choi et al., 2016) and Calretinin(Radi and Miller, 2005) respectively. The astrocytes including their bodies and their processes showed the positive immune-reaction of GFAP in the form of cytoplasmic brown granules (Highley and Sullivan, 2013). The positive immune-reaction of calretinin appeared as brown cytoplasmic and nuclear staining pattern with nuclear positivity considered to be more sensitive and specific (Szalak et al., 2015). Negative control slides were preparedfrom cerebellum by the same steps except they were incubated with antibody diluent instead of primary antibody.

\section{Image analysis:-}

The percentage $(\%)$ of the areas positively immune-stained with GFAP and calretinin in the three layers of the cerebellar cortex was estimated in all groups. Six immune-stained slides were examined from each specimen and six high-power fields (x400) from the three layers of the cerebellar cortex in each slide were randomly chosen. The $\%$ area of GFAP and calretinin positive immune-staining were digitized using Olympus® digital camera installed on an Olympus® BH-2, microscope (Tokyo, Japan) with $1 / 2 \times$ photo adaptor, using $40 \times$ magnification of an objective lens.

\section{Statistical analysis:-}

Statistical data were expressed as arithmetic mean \pm standard deviation (SD). Student t-test was used to test the significant change in the parameters in different groups of the study in comparison to control group I as well as to test the significance between groups II \&III. Statistical analysis of the data was done by MedCalc software for medical statistics with a statistical significance realized at probability $\mathrm{P}<0.05$ (Schoonjans et al., 1995).

\section{Results:- \\ Light microscopic examination:- Group I:-}

In sections stained with haematoxylin and eosin, the cerebellar folia of control animals were covered with epidura containing blood vessels. Cerebellar cortex was formed of an outer molecular layer, a middle Purkinje cell layer and an inner granular layer. The molecular layer contained radially directed fibers and glial cells (stellate and basket cells). The Purkinje cell layer showed large flask shaped Purkinje cells with apical dendrites and central vesicular nuclei regularly arranged in one row. They were surrounded by Bergmann glia with vesicular nuclei. The granular layer contained numerous small granule cells with darkly stained nuclei surrounding homogenous eosinophilic cerebellar glomeruli. In all layers the neuropil which is formed of the cellular processes of the neurons and glial cells appeared homogenous with a minimal extracellular space (Fig. 1a). Toluidine blue stained sections revealed Nissl granules in the soma and apical dendrite of Purkinje cells (Fig. 1b). Human cerebral cortex was used as a positive control to demonstrate the positive immune-reaction for GFAP in the astrocytes and their processes (Fig. 1c). In group I, a positive immune-reaction for GFAP was seen in the radial fibers of the molecular layer, in Bergmann glia of Purkinje cell layer and in the cerebellar glomeruli in the granular layer (Fig. 1d). Human testis was used as a positive control for calretinin to demonstrate the positive immune-reaction in the nuclei and cytoplasm of interstitial 
cells of Leydig (Fig. 1e). The cerebellar cortex in group I showed a positive calretinin immune- reaction in the fibers of molecular layer, Bergmann glia, cerebellar glomeruli and in the cells of the granular layer. On the other hand, Purkinje cells showed nearlya negative immune-reaction (Fig. 1f). The mean values of \% area of GFAP and calretinin in group I were demonstrated in tables 1 and 2.

\section{Group II:-}

Sections stained with haematoxylin and eosin showed the epidura with dilated congested blood vessels (Fig. 2a). Some Purkinje cells showed vesicular nuclei and others appeared degenerated with darkly stained cytoplasm and condensed nuclei. The nuclei of some Bergmann glia were condensed. The neuropil appeared mildly vacuolated (Fig. 2b). Toluidine blue stained sections revealed the presence of Nissl granules in some Purkinje cells, while other Purkinje cells showed chromatolysis of Nissl granules (Fig. 2c). A Positive immune- reaction of GFAP was detected in the fibers of molecular and granular layers. Some Bergmann glial cells showed a negative reaction while others demonstrated a positive reaction. The axons of basket cells that surrounded the Purkinje cell bodies showed a positive reaction as well (Fig. 2d). The mean value of the $\%$ area of the positive immune-stain for GFAP was insignificant $(\mathrm{P}>0.05)$ increased in the molecular and granular layers, while it showed a significant $(\mathrm{P}<0.05)$ decrease in the Purkinje cell layer, as compared to group I (Table 1). There was a positive calretinin immunereaction in the fibers of the molecular layer, the cells and fibers of granular layer, Purkinje cells and Bergmann glial cells (Fig. 2e). The mean value of the \% area of the positive immune-stain for calretinin was insignificantly $(\mathrm{P}>$ $0.05)$ decreased in the granular layer and significantly $(\mathrm{P}<0.05)$ increased in the Purkinje cell layer as compared to group I (Table 2).

\section{Group III:-}

Sections stained with haematoxylin and eosin showed the presence of congested blood vessels and inflammatory cells in the surrounding epidura (Fig. 3a). The Purkinje cells were distorted and showed cellular shrinkage in addition to pyknosis or karyorrhexis of some nuclei. The nuclei of many Bergmann glia were condensed. The glomeruli between granular cells were shrunken. The surrounding neuropil tissue was highly vacuolated leaving empty spaces (Fig. 3b). In Toluidine blue stained sections, almost all the Purkinje cells showed disintegration and chromatolysis of Nissl granules (Fig. 3c). A Positive immune-reaction for GFAP was noted in the radial fibers of the molecular layer and in the granular layer. All Bergmann glial cells showed a negative reaction (Fig. 3d). The mean values of the $\%$ area of the positive immune-stain for GFAP were significantly $(\mathrm{P}<0.05)$ increased in the molecular and granular layers as compared to group I and group II, while they were significantly $(\mathrm{P}<0.05)$ decreased in the Purkinje cell layer as compared to group I and group II (Table 1). Calretinin immune-reaction was positive in; the fibers of the molecular layer, few Purkinje cells, and few cells of the granular layer (Fig. 3e). The \% area of the positive immune-stain for calretinin was significantly $(\mathrm{P}<0.05)$ decreased in the molecular and granular layers as compared to group I and group II. In Purkinje cell layer, the \% area for calretinin was significantly (P < $0.05)$ increased as compared to group I and significantly $(\mathrm{P}<0.05)$ decreased as compared to group II (Table 2$)$.

Table 1:- Mean values \pm S.D of \% area of GFAPimmune-stainin the groups of the experiment.

\begin{tabular}{|l|l|l|l|l|}
\hline & Group I & Group II & Group III & Significance \\
\hline Molecular layer & $14.4800 \pm 2.4760$ & $15.9300 \pm 1.6720$ & $25.7000 \pm 2.3333$ & $\begin{array}{l}\mathrm{P} 1=0.1422 \\
\mathrm{P} 2<0.0001^{*} \\
\mathrm{P} 3<0.0001^{*}\end{array}$ \\
\hline Purkinje cell layer & $17.7700 \pm 2.2642$ & $12.1100 \pm 1.2215$ & $10.2600 \pm 1.0069$ & $\begin{array}{l}\mathrm{P} 1<0.0001^{*} \\
\mathrm{P} 2<0.0001^{*} \\
\mathrm{P} 3<0.0001^{*}\end{array}$ \\
\hline Granular layer & $14.4000 \pm 1.8547$ & $15.5800 \pm 1.2453$ & $22.9200 \pm 2.1948$ & $\begin{array}{l}\mathrm{P} 1=0.1122 \\
\mathrm{P} 2<0.0001 * \\
\mathrm{P} 3<0.0001^{*}\end{array}$ \\
\hline
\end{tabular}

$*=$ significant change $(\mathrm{P}<0.05)$ by student t-test.

$\mathrm{P} 1$ = comparison between group I and group II.

P2 = comparison between group I and group III

P3 = comparison between group II and group III. 
Table 2:- Mean values \pm S.D of $\%$ area of calretininimmune-stainin the groups of the experiment.

\begin{tabular}{|c|c|c|c|c|}
\hline & Group I & Group II & Group III & Significance \\
\hline Molecular layer & $14.2862 \pm 1.8821$ & $14.4100 \pm 1.2333$ & $3.0600 \pm 0.4926$ & $\begin{array}{l}\mathrm{P} 1=0.8638 \\
\mathrm{P} 2<0.0001^{*} \\
\mathrm{P} 3<0.0001^{*}\end{array}$ \\
\hline Purkinje cell layer & $1.3200 \pm 0.6763$ & $12.6100 \pm 1.1770$ & $9.1900 \pm 1.2758$ & $\begin{array}{l}\mathrm{P} 1<0.0001^{*} \\
\mathrm{P} 2<0.0001^{*} \\
\mathrm{P} 3<0.0001^{*}\end{array}$ \\
\hline Granular layer & $21.7100 \pm 3.4223$ & $19.5900 \pm 1.5609$ & $5.0100 \pm 0.9504$ & $\begin{array}{l}\mathrm{P} 1=0.0916 \\
\mathrm{P} 2<0.0001^{*} \\
\mathrm{P} 3<0.0001^{*}\end{array}$ \\
\hline
\end{tabular}

$*=$ significant change $(\mathrm{P}<0.05)$ by student t-test.

$\mathrm{P} 1$ = comparison between group I and group II.

$\mathrm{P} 2$ = comparison between group I and group III

P3 = comparison between group II and group III.

\section{Figures:-}
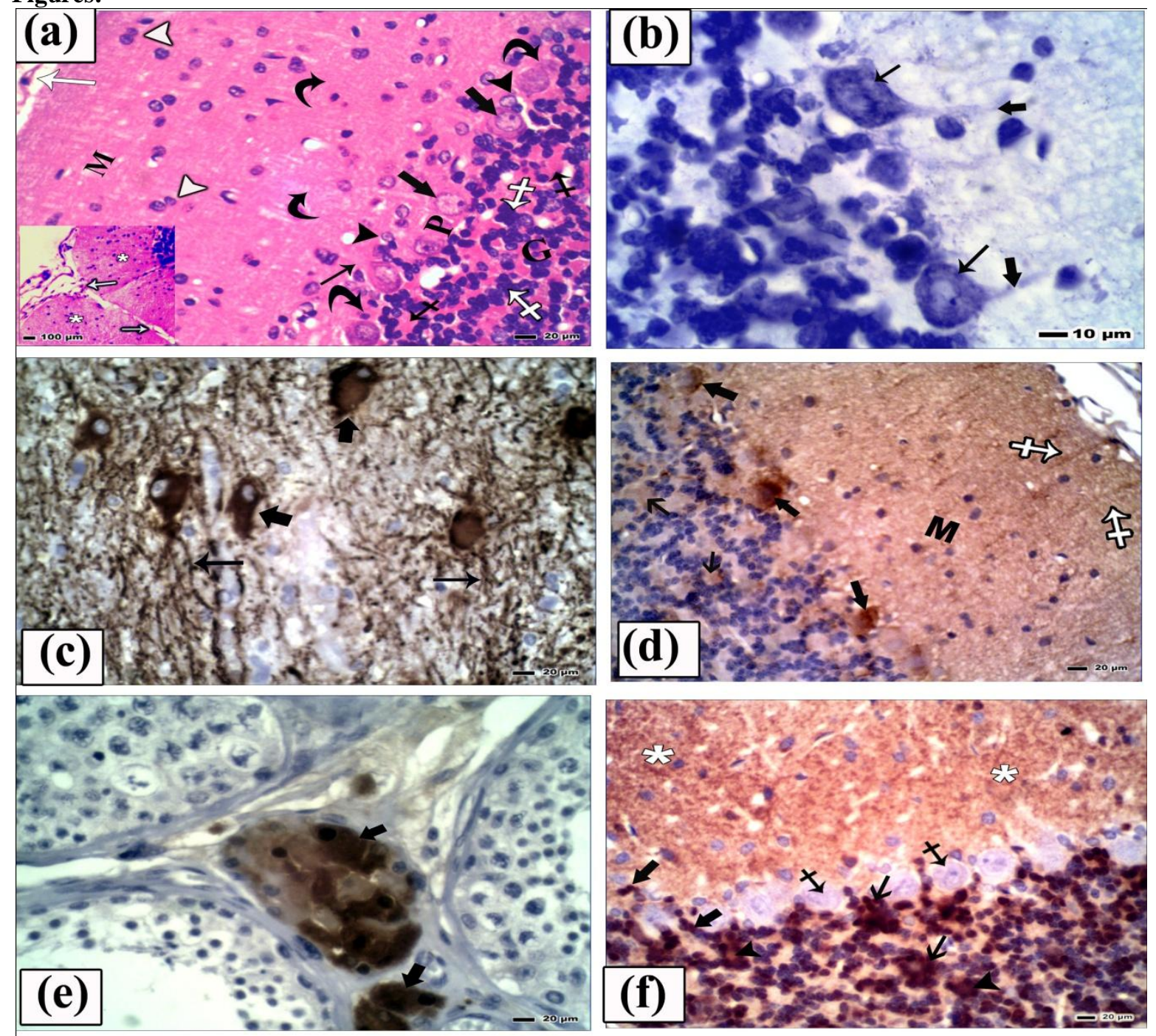

Fig 1:- Cerebellar cortex in group I. (a): Cerebellar folia (asterisks) are surrounded by epidura with non- congested blood vessels (white arrows). The cortex is formed of; molecular layer (M), Purkinje cells layer (P) and granular layer $(\mathrm{G})$. Note the nuclei of glial cells in the molecular layer (white arrowheads). The Purkinje cell layer contains one row of regularly arranged large flask shaped cells with vesicular nuclei (thick arrows) and apical dendrites 
(black arrow). The cells are surrounded with Bergmann glia astrocytes that show vesicular nuclei (black arrowheads). The granular layer contains small granule cells with dark nuclei (white crossed arrows) that surround homogenous eosinophilic glomeruli (black crossed arrows). The neuropil is homogenous with a minimal extracellular space (curved arrows) [H\&E x 400, inset x100]. (b): Purkinje cells contain blue stained Nissl granules (arrows) around the vesicular nucleus and in the apical dendrites (thick arrows) [Toluidine blue x1000]. (c): Human cerebral cortex is used as a positive control to demonstrate the positive immune-reaction for GFAP in the astrocytes (thick arrows) and their processes (arrows) [IHC for GFAPx400]. (d):Cerebellar cortex in group I shows a positive reaction of GFAP in the radial fibers (white crossed arrows) of the molecular layer (M), in the Bergmann glia of Purkinje cell layer (thick arrows) and in the cerebellar glomeruli of the granular layer (arrows) [IHC for GFAPx400]. (e): Human testis is used as a positive control to demonstrate the positive immune-reaction for calretinin in the nuclei and cytoplasm of the interstitial cells of Leydig (thick arrows) [IHC for calretininx400]. (f): Cerebellar cortex in group I shows a positive calretinin immune-reaction in; fibers of the molecular layer (asterisks), Bergmann glial cells (thick arrows), cerebellar glomeruli (arrow heads), and in the cells of the granular layer (arrows). Note the negative immune- reaction in Purkinje cells (crossed arrows) [IHC for calretinin x 400].
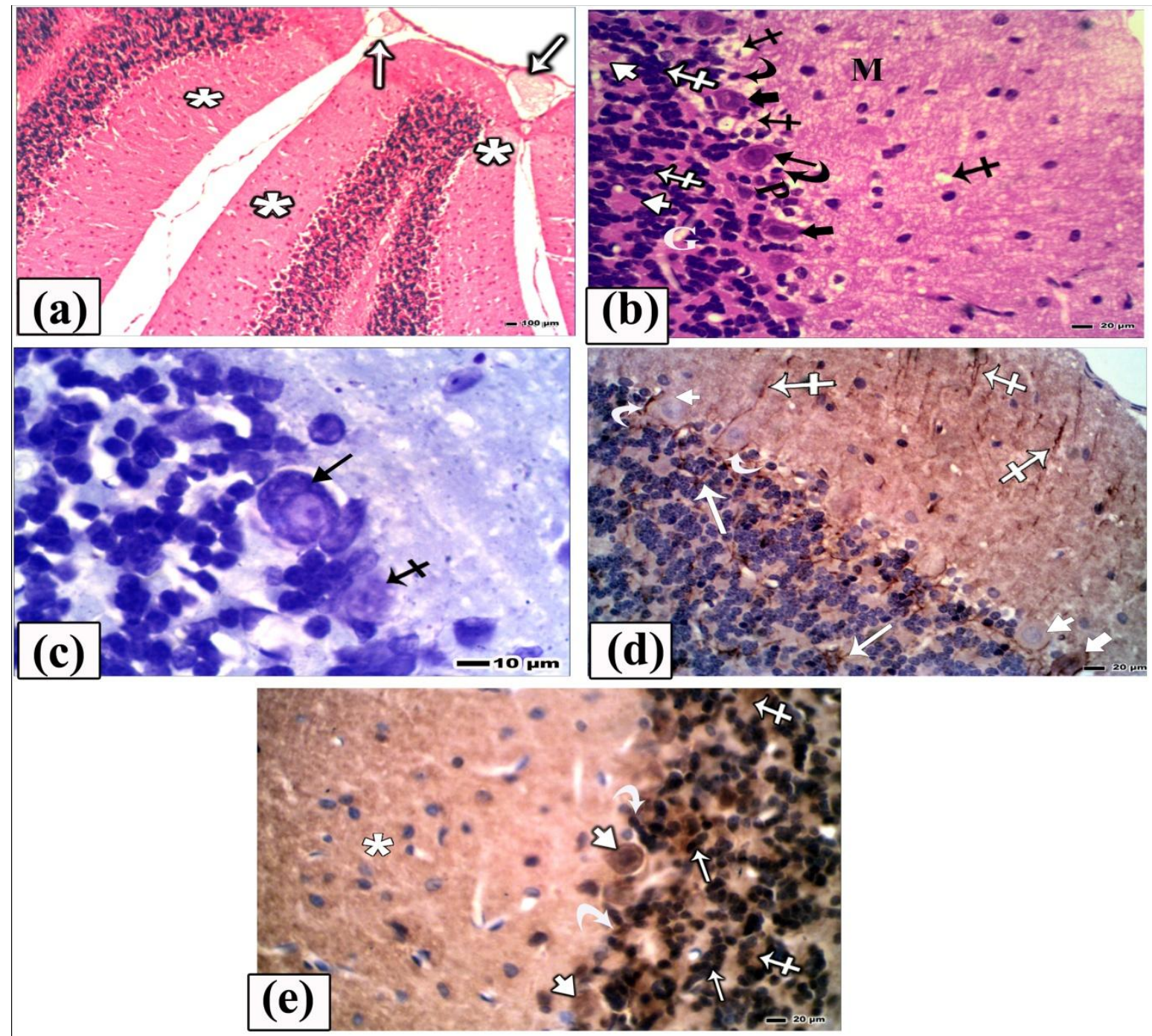

Fig 2: Cerebellar cortex in group II. (a): The cerebellar folia (asterisks) are surrounded by epidura with dilated congested blood vessels (arrows) [H\&Ex100]. (b): Showing molecular layer (M), one row of regularly arranged Purkinje cells (P) some of them with vesicular nuclei (arrow) and others appear degenerated with darkly stained cytoplasm and condensed nuclei (thick arrows). The nuclei of some Bergmann glia were condensed (curved arrows). The granular layer (G) contains small granule cells (white crossed arrows) and cerebellar glomeruli (white small arrows). The neuropil is vacuolated (black crossed arrows) [H\&E x 400]. (c): some Purkinje cells show Nissl 
granules (arrow), while others show chromatolysis of Nissl granules (crossed arrow) [Toluidine blue x1000]. (d): Apositive immune-reaction for GFAP is detected in the radial fibers of the molecular (crossed arrows) and granular (arrows) layers. Some Bergmann glial cells in Purkinje cell layer show immune-reaction (thick arrow) and others have a negative reaction (short arrows). The axons of basket cells with a positive reaction surround the base of Purkinje cells (curved arrows) [IHC for GFAP x 400]. (e): A positive calretinin immune-reaction is detected in the cells of the granular layer (arrows), the glomeruli (crossed arrows) and the fibers (asterisk) of the molecular layer. Note the immune-reaction in the Purkinje cells (short arrows) and Bergmann glial cells (curved arrows) [IHC for calretinin $\mathrm{x}$ 400].
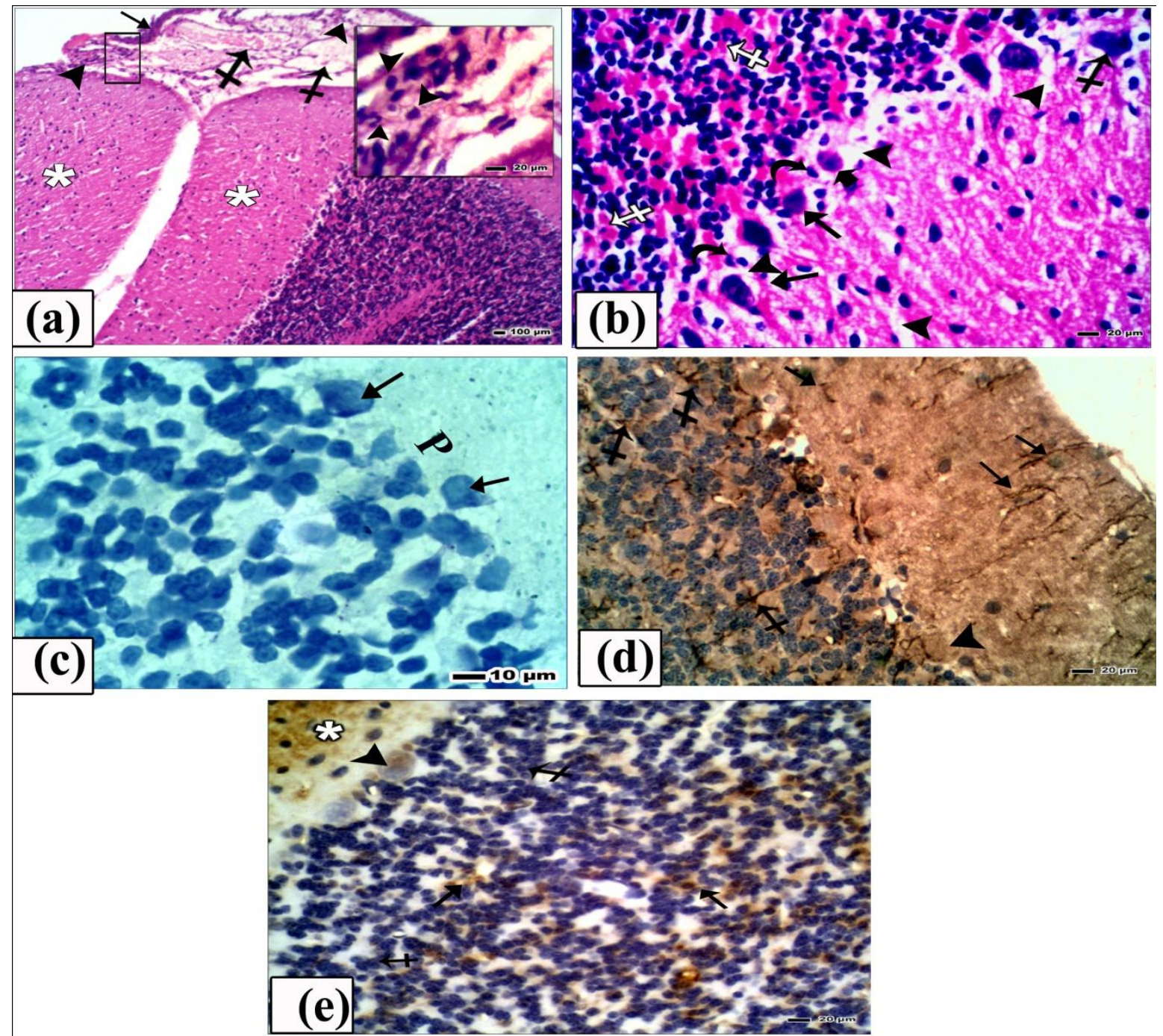

Fig 3:- Cerebellar cortex in group III. (a): Congested blood vessels (crossed arrows) and inflammatory cells (arrow heads) are seen in the epidura (arrow) surrounding the cerebellar folia (asterisks). The inset is a higher magnification of the boxed area [H\&E x 100, inset x400]. (b): Purkinje cells are distorted with cellular shrinkage (arrows). Note the pyknotic nuclei (black crossed arrow) and karyorrhexis of some nuclei (thick arrow). Many nuclei of Bergmann glia are condensed (curved arrows). The glomeruli between granule cells appear shrunken (white crossed arrows). The neuropil tissue is highly vacuolated leaving empty spaces (arrow heads) [H\&E x 400]. (c): ManyPurkinje cells (P) show disintegration and chromatolysis and disintegration of their Nissl granules (arrows) [Toluidine blue x1000]. (d): A positive immune-reaction for GFAP is seen in the radial fibers of the molecular (arrows), granular layers (crossed arrows). All Bergmann glial cells show a negative reaction (arrow head) [IHC for FGAPx400]. (e): positive immune-reaction is seen in; the fibers of the molecular layer (asterisk), few Purkinje cells (arrow head), and in few cells in granular layer (arrows). Note the negative reaction (crossed arrows) in the other cells in granular layer [IHC for calretinin $\mathrm{x}$ 400]. 


\section{Discussion:-}

Major depressive disorder is one of the most common psychiatric disorders (Kessler et al., 2005). Therefore, there is a pressing need to develop therapeutics that are capable of relieving the depressive symptoms for patients unable to respond to conventional therapies (Browne and Lucki, 2013).

This study investigated one of the promising antidepressant drugs, ketamine. The psychotomimetic properties and abuse potential of ketamine necessitate caution in promoting this particular compound as a general treatment for the major depressive disorder. It is crucial to use the appropriate dose of ketamine after realizing the microscopic structural alteration in the cerebellar cortex as a template of the nervous system in response to protracted variable doses of ketamine. It was postulated that repeated infusions of ketamine produced a more durable antidepressant response when compared to a single infusion(Murrough et al., 2013). Therefore, the rats in this study received two different doses of ketamine every 12 hours for 14 consecutive days. The administration of a low dose of ketamine (5 $\mathrm{mg} / \mathrm{kg}$ ) in group II produced minimal structural changes, while the administration of a higher dose of ketamine (20 $\mathrm{mg} / \mathrm{kg}$ ) in group III resulted in sever neuronal degenerative structural changes and vacuolation in the neuropil. It was suggested thatvacuolation within the cerebellar layers could be due to swelling and degeneration of neuronal processes (Garman, 2011). In group III of the present study, the blood vessels were congested and contained inflammatory cells. It has been found that ketamine may induce a moderate vascular inflammation (Linet al., 2015).

Bosnjak et al. (2012) demonstrated a significant decrease in neuronal viability when ketamine concentration was raised to greater than $2000 \mu \mathrm{M}$. High doses of ketamine were reported to induce degenerative changes in other nervous tissues including the spinal cord (Vranken et al., 2005), rat hippocampus (Karacaet al., 2015) andin the brain cerebraltissue (Zou et al., 2009). Ketamine-treated neurons were found to undergo mitochondria-mediated apoptosis through increased caspase-3 activity and DNA damage. It has been reported that ketamine increased reactive oxygen species (ROS) production and induced differential expression of oxidative stress-related genes (de Oliveira et al., 2009; Zuo et al., 2007; Bosnjak et al., 2012). It was postulated that continuous stimulation of the receptor NMDA via ketamine may activate neural damage and apoptotic neural cell death (Wang et al., 2004).

The immunohistochemical expression of glial fibrillary acidic protein (GFAP) was assessed in the present study. In control group I, a positive immune-reaction for GFAP was demonstrated in the radial fibers of the molecular layer, Purkinje cell layer, and in the granular layers. These results were consistent with (Sawantet al., 1994). It has been postulated that GFAP is important for astrocyte-neuronal interactions. GFAP-mediated astrocytic processes play a vital role in modulating synaptic efficacy in the CNS. In addition, GFAP expression is essential for normal white matter architecture and blood- brain barrier integrity (Sriram et al., 2004).

In group II of the present study, the cerebellar cortex showed a positive immune- reaction of GFAP in the fibers of molecular layer and granular layers. This reaction was significantly increased in the same layers of group III. It was postulated that after any degenerative insult, astrocytes react rapidly by producing more GFAP, leading to vigorous astrogliosis (Sriram et al., 2004). Therefore, common pathological hallmarks of several neurodegenerative diseases include the loss of invaluable neurons associated with or followed by massive activation of astrocytes (Yu et al., 1993). Furthermore, it was postulated that the mechanism of ketamine to act as a rapid antidepressant is mediated through the activation of glutamate receptors by NDMA antagonism; glutamate which is released and stimulates postsynaptic glutamate receptors. When activated, these receptors stimulate a signal transduction pathway that leads to production of dendritic spines (Browne and Lucki, 2013), and increase astrocyte proliferation (Liao and Chen, 2001).

Unexpectedly, the Bergmann glia in Purkinje cell layer showed a decrease in GFAP immune-reaction in group II, with almost no reaction to be found in group III of the present study. It was found that GFAP is required for communications between Bergmann glia and Purkinje cells (Shibuki et al., 1996). The decrease in GFAP expression in Bergmann glia may be explained on the bases of the degenerative changes encountered in the cells in H\&E stained sections. Furthermore, it has been demonstrated that repeated infusions of ketamine leads to loss of tubules and cytoskeletal filaments (Bosnjak et al., 2012). It was found that affected Bergmann glia can lead to loss of Purkinje cell shape and their disorientation (Laure-Kamionowska and Maślińska 2007).

The immunohistochemical expression of calretinin was assessed in the present study, as well. In control group I, Purkinje cells showed no reaction, while a positive calretinin immune-reactivity was detected in the fibers of the molecular layer and in Bergmann glia cells. It has been reported that Bergmann glial cells display calcium transients 
in response to glutamate, so they play a role in controlling the membrane potential and thereby the activity of adjacent Purkinje cells (Wang et al., 2000). In addition, a positive calretinin immune-reaction was found in cerebellar glomeruli and in the granular layer. It has been proved that calretinin expression in granule cells was necessary for correct computation that is crucial for the coding and storage of information in the cerebellum (Schwaller, 2014). Furthermore, in the granular layer, the unipolar brush cells have been reported to exhibit a positive calretinin immune-reactivity as well. Unipolar brush cells represent a unique neuroendocrine component of the mammalian cerebellar cortex (Nunzi and Mugnaini 2009). They are excitatory interneurons located in the granular layer (Ito, 2006). It has a single, short dendrite terminating in a brush of dendrioles that receives glutamatergic input on the brush from an individual mossy fiber (Diño et al., 2000).

The administration of ketamine in group II and III of the current study resulted in a decrease in calretinin immunereactivity in granular layer. It was found that repeated exposures to ketamine lead to a reduction in the expression of calcium-binding protein in the interneurons in rodents and nonhuman primates (Cochran et al., 2003). Furthermore, a decrease in calretinin expression in granule cells as a result of calcium channel dysfunction was found to cause abnormal neuronal excitability (Nahm et al., 2002). As proof-of-concept that regulating calcium homeostasis may be a key to protect the brain from anesthesia-induced injury, ketamine was found to cause a loss of calcium, which leads to mitochondrial dysfunction, cytochrome $C$ release and activation of caspase-3 (Turner et al., 2009) .It has been reported that the absence of calretinin causes impairment in the motor control in mouse cerebellum (Schiffmann 1999).

In the present study, calretinin showed an interesting pattern of expression in Purkinje cells. In group II, Purkinje cells showed a significant increase in calretinin immune- reaction as compared to control group I. However, in group III they showed a significant decrease in the reaction as compared to group II. It has been demonstrated that incalretininknockout mice, the cerebellum resulted in an unexpected positive calretininimmunoreactivity in Purkinje cells and in marked abnormalities in the Purkinje cell firing with alterations of both simple and complex spikes (Schiffmann 1999). The increased immunoreactivity of the Purkinje cells in group II may suggests adaptive mechanisms to fight against the neurodegeneration(Toledano et al. 2012). On the other hand, the decrease in the immunoreactivity of the Purkinje cells in group III may be due to the massivedegeneration of many Purkinje cells, as it was reportedthat the neuronal degeneration resulted ina decrease in calretinin expression in the hippocampus and cerebellum (Byun et al. 2012)

\section{Conclusion:-}

Building a bridge between the different doses of ketamine as antidepressant and the changes in neuronal structure revealed that the protracted administration of a high dose of ketamine could induce structural and immunohistochemical alterations in the cerebellar cortex; suggesting that the use of small doses is much safer.

\section{Recommendations:-}

A wider collaboration among laboratory investigators and clinician-scientists will explicate the neurotoxic effects of large doses of ketamine and promote safe and effective clinical use of ketamine as an antidepressant in the future.

\section{Declaration of interest:-}

The authors report no conflicts of interest. The authors alone are responsible for the content and writing of this paper.

\section{References:-}


1. Akscyn R.M., Franklin J.L., Gavrikova T.A. and Messina J.L. (2016 ): Skeletal muscle atrogene expression and insulin resistance in a rat model of polytrauma. Physiol Rep. 4(2). pii: e12659.

2. Alvarez M.I., Lacruz C., Toledano-Díaz A., Monleón E., Monzón M., Badiola J.J. and Toledano A. (2008): Calretinin-immunopositive cells and fibers in the cerebellar cortex of normal sheep. Cerebellum. 7 (3):417-29.

3. Bosnjak Z.J., Yan Y., Canfield S., Muravyeva M.Y., Kikuchi C., Wells C.W., Corbett J.A. and Bai X.(2012): Ketamine induces toxicity in human neurons differentiated from embryonic stem cells via mitochondrial apoptosis pathway. Curr Drug Saf. 7(2):106-19.

4. Browne C. and Lucki I.(2013): Antidepressant effects of ketamine: mechanisms underlying fast-acting novel antidepressants. Frontiers Pharmacol. 4(12):1-18.

5. Byun K., Kim D., Bayarsaikhan E., Kim Oh. J., Kwak G., Jeong G. B., JoS. M. and Lee, B.(2013): "Changes of calcium binding proteins, c-Fos and COX in hippocampal formation and cerebellum of NiemannPick, type C mouse," J ChemNeuroanat. 52, 1-8.

6. CallaghanJ. P. O. and SriramK. (2005): Glial fibrillary acidic protein and related glial proteins as biomarkers of neurotoxicity. 4(3):433-42.

7. Choi I., Choi D.J., Yang H., Woo J.H., Chang M.Y., Kim J.Y., Sun W., Park S.M., Jou I., Lee S.H. and Joe E.H.(2016): PINK1 expression increases during brain development and stem cell differentiation, and affects the development of GFAP-positive astrocytes. Mol Brain. 8; 9(1):5.

8. Cochran S.M., Kennedy M., McKerchar C.E., Steward L.J., Pratt J.A. and Morris B.J. (2003): Induction of metabolic hypofunction and neurochemical deficits after chronic intermittent exposure to phencyclidine: differential modulation by antipsychotic drugs. Neuropsychopharmacology, 28, 265-275.

9. de Oliveira L., Spiazzi C.M., Bortolin T., Canever L., Petronilho F., Mina F.G., Dal-Pizzol F., Quevedo J. and Zugno A.I. (2009): Different sub-anesthetic doses of ketamine increase oxidative stress in the brain of rats. ProgNeuropsychopharmacolBiol Psychiatry 33:1003-1008.

10. Diño M.R., Schruerger R.J., Liu J.B., Slater N.T. and Mugnaini E. (2000): Unipolar brush cell: a potential feedforward excitatory interneuron of the cerebellum. Neuroscience 98: 625-636.

11. Dong C. and Anand K.J. (2013): Developmental neurotoxicity of ketamine in pediatric clinical use. ToxicolLett. 20;220(1):53-60.

12. Edmonds B., Reyes R., Schwaller B. and RobertsW.M. (2000): Calretinin modifies presynaptic calcium signaling in frog saccular hair cells. Nat Neurosci 3:786-790.

13. Floris A., Diño M., Jacobowitz D.M. and Mugnaini E. (1994): The unipolar brush cells of the rat cerebellar cortex and cochlear nucleus are calretinin-positive: a study by light and electron microscopic immunocytochemistry. AnatEmbryol (Berl). 189(6):495-520.

14. Gall D, Roussel C., Susa I., D'Angelo E., Rossi P., Bearzatto B., Galas M.C., Blum D., Schurmans S. and Schiffmann SN. (2003): Altered neuronal excitability in cerebellar granule cells of mice lacking calretinin. J Neurosci. 15;23(28):9320-7.

15. Garman R.H. (2011): Histology of the central nervous system. ToxicolPathol. 39(1):22-35.

16. Hart H. (2011): The cerebellum, cognition, behaviour. Dev Med Child Neurol 53: 1069-1070.

17. Highley J.H. andsullivan, N. (2013): "Techniques in neuropathology in theory and practice of histological technique," 7th ed. Churchil Livingstone of El Sevier, Philadelphia, USA.; pp. 353-380.

18. Horvath G., Kekesia G., Tuboly G. and Benedek G. (2007): Antinociceptive interactions of triple and quadruple combinations of endogenous ligands at the spinal level. Brain Res. 1155: 42-48.

19. Ito H., Uchida T. and Makita K. (2015): Ketamine causes mitochondrial dysfunction in human induced pluripotent stem cell-derived neurons. PLoS One. 28;10(5):e0128445.

20. Ito M. 2006. Cerebellar circuitry as a neuronal machine. ProgNeurobiol 78: 272-303.

21. Karaca M.O., Süren M., Karaca Z.í., Arıcı S., Karaman S., Aslan H., Kaya Z. and Doğru S. (2015): Repeated dose of ketamine effect to the rat hippocampus tissue. Saudi J Anaesth. 9(3):289-92.

22. Kessler R. C., Chiu W. T., Demler O., Merikangas K. R. and Walters E. E. (2005): Prevalence, severity, and comorbidity of 12-month DSM-IV disorders in the National Comorbidity Survey Replication. Arch Gen Psychiatry 62, 617-627.

23. Labombarda F., Coronel M.F., Villar M.J., Nicola A.F. and González S. L. (2008): Neuropathic pain and temporal expression of preprodynorphin, protein kinase $\mathrm{C}$ and $\mathrm{N}$-methyl-D-aspartate receptor subunits after spinal cord injury. Neurosci. Lett. 447: 115-119.

24. Laure-Kamionowska M. and Maślińska D. (2007): Astroglia and microglia in cerebellar neuronal miration disturbances. Folia Neuropathol. 45(4):205-12.

25. Liao S.L. and Chen C. J. (2001): Neuroreport. 12:3519. 
26. Lin H.C., Lee H.S., Chiueh T.S., Lin Y.C., Lin H.A., Lin Y.C., Cha T.L. and Meng E. (2015): Histopathological assessment of inflammation and expression of inflammatory markers in patients with ketamine-induced cystitis. Mol Med Rep. 11(4):2421-8.

27. Murrough J.W., Perez A.M., Pillemer S., Stern J., Parides M.K., aan het Rot M., Collins K.A., Mathew S.J., Charney D.S. and, Iosifescu D.V. (2013): Rapid and longer term antidepressant effects of repeated ketamine infusions in treatment-resistant major depression. Biol Psychiatry 74: 250-256.

28. NahmS. S., TomlinsonD. J. and AbbottL. C.(2002): "Decreased calretinin expression in cerebellar granule cells in the leaner mouse," J Neurobiol., vol.51, no. 4, pp. 313-22.

29. Niciu M.J., Luckenbaugh D.A., Ionescu D.F., Mathews D.C., Richards E.M. and JrZarate C.A. (2013): Subanesthetic dose ketamine does not induce an affective switch in three independent samples of treatment-resistant major depression. Biol Psychiatry. 15;74(10):e23-4.

30. Nunzi M.G. and Mugnaini E.(2009): Aspects of the neuroendocrine cerebellum: expression of secretogranin II, chromogranin A and chromogranin B in mouse cerebellar unipolar brush cells. Neuroscience. 1;162 (3):67387.

31. Ordek G, Groth JD and Sahin M. (2013): Differential effects of ketamine/xylazine anesthesia on the cerebral and cerebellar cortical activities in the rat. J Neurophysiol. 109(5):1435-43.

32. Parise,E.M.,Alcantara,L.F.,Warren,B.L.,Wright,K.N.,Hadad,R.,Sial,O. Kroeck K. G., Iñiguez S. D. and Bolaños-Guzmán C. A. (2013): "Repeated Ketamine Exposure Induces an Enduring Resilient Phenotype in Adolescent and Adult Rats," Biol. Psychiatry, 74, 750-759,.

33. Price R.B., Iosifescu D.V., Murrough J.W., Chang L.C., Al Jurdi R.K., Iqbal S.Z., Soleimani L., Charney D.S., Foulkes A.L. and Mathew S.J. (2014): Effects of ketamine on explicit and implicit suicidal cognition: a randomized controlled trial in treatment-resistant depression. Depress Anxiety. 31(4):335-43.

34. Radi Z.A. and Miller D.L. (2005):Immunohistochemical expression of calretinin in canine testicular tumours and normal canine testicular tissue. Res Vet Sci. 79(2):125-9.

35. Sawant L.A., Hasgekar N.N.and Vyasarayani L.S. (1994): Developmental expression of neurofilament and glial filament proteins in rat cerebellum. Int J Dev Biol.; 38(3):429-37.

36. Schiffmann S. N., CheronG., LohofA., AlcantaraP. d., MeyerM., ParmentierM. and SchurmansS. (1999): Impaired motor coordination and Purkinje cell excitability in mice lacking calretinin," ProcNatlAcadSci U S A., vol. 96, no. 9, pp. 5257-5262.

37. Schoonjans F., Zalata A., Depuydt C. and Comhaire F. (1995): MedCalc: a new computer program for medical statistics. Computer Methods and programs in Biomedicine. 48: 257-262.

38. Schwaller B. (2014): Calretinin: from a "simple" $\mathrm{Ca}(2+)$ buffer to a multifunctional protein implicated in many biological processes. Front Neuroanat. 5;8:3. E Collection 2014.

39. Shibuki K, Gomi H, Chen L, Bao S, Kim JJ, Wakatsuki H, Fujisaki T, Fujimoto K, Katoh A, Ikeda T, Chen C, Thompson RF, Itohara S. (1996 ): Deficient cerebellar long-term depression, impaired eyeblink conditioning, and normal motor coordination in GFAP mutant mice. Neuron. 16(3):587-99.

40. Sos P., Klirova M., Novak T., Kohutova B., Horacek J. and Palenicek T. (2013): Relationship of ketamine's antidepressant and psychotomimetic effects in unipolar depression. NeuroEndocrinolLett. 34(4):287-93.

41. Sriram K., Benkovic S.A., Hebert M.A., Miller D.B. and O'Callaghan J.P. (2004): Induction of gp130related cytokines and activation of JAK2/STAT3 pathway in astrocytes precedes up-regulation of glial fibrillary acidic protein in the 1-methyl-4-phenyl-1,2,3,6-tetrahydropyridine model of neurodegeneration: key signaling pathway for astrogliosis in vivo? J BiolChem 279:19936 -19947.

42. Suvarna K, Layton C. and Bancroft J. (2013):Theory and Practice of Histological Techniques. 7th ed., Churchil Livingstone of El Sevier, Philadelphia, USA. p173-220.

43. Szalak R., Matysek M., Mozel S. and Arciszewski M.B. (2015):Immunocytochemical detection of calretinin in the claustrum and endopiriform nucleus of the chinchilla. Pol J Vet Sci. 18(4):857-63.

44. Tizabi Y., Bhatti B.H., Manaye K.F., Das J.R. and Akinfiresoye L. (2013): Antidepressant-like effects of low ketamine dose is associated with increased hippocampal AMPA/NMDA receptor density ratio in female Wistar-Kyoto rats. Neuroscience. 28; 72-80.

45. Toledano A., Alvarez M.I., Monleón E., Toledano-Díaz A., Badiola J.J. and Monzón M. (2012 ): Changes induced by natural scrapie in the calretinin-immunopositive cells and fibres of the sheep cerebellar cortex. Cerebellum.

46. Turner C.P., DebenedettoD.and Liu C. (2009): NMDAR blockade-induced neonatal brain injury: Reversal by the calcium channel agonist BayK 8644. NeurosciLett. 450:292-295. 
47. Valiullina F., Zakharova Y., Mukhtarov M., Draguhn A., Burnashev N. and Rozov A. (2016 ): The Relative Contribution of NMDARs to Excitatory Postsynaptic Currents is Controlled by Ca(2+)-Induced Inactivation. Front Cell Neurosci. 29;10:12.

48. Venâncio C., Magalhães A., Antunes L. and Summavielle T. (2011): Impaired spatial memory after ketamine administration in chronic low doses. CurrNeuropharmacol. 9(1):251-5.

49. Vranken J.H., Troost D., Wegener J.T., Kruis M.R. and van der Vegt M.H. (2005):Neuropathological findings after continuous intrathecal administration of $S(+)$-ketamine for the management of neuropathic cancer pain. Pain. 117(1-2):231-5.

50. Wang C., Anastasio N., Popov V., Leday A. and Johnson K.M. (2004): Blockade of N-methyl-D-aspartate receptors by phencyclidine causes the loss of corticostriatal neuronsNeuroscience. 125(2):473-83.

51. Wang F., Xu Q., Wang W., Takano T. and Nedergaard M. (2012): Bergmann glia modulate cerebellar Purkinje cell bistability via Ca2+-dependent K+ uptake. ProcNatlAcadSci U S A. 15;109(20):7911-6.

52. Young C., Jevtovic-Todorovic V., Qin Y.Q., Tenkova T., Wang H., Labruyere J. and Olney J.W.(2005): Potential of ketamine and midazolam, individually or in combination, to induce apoptotic neurodegeneration in the infant mouse brain. Br J Pharmacol 146:189 -97

53. Yu A.C., Lee Y.L. and Eng L.F. (1993):Astrogliosis in culture: I. The model and the effect of antisense oligonucleotides on glial fibrillary acidic protein synthesis. J Neurosci Res. 15; 34(3):295-303.

54. Zou X., Patterson T.A., Divine R.L., Sadovova N., Zhang X., Hanig J.P., Paule M.G., Slikker W. Jr. and Wang C. (2009): Prolonged exposure to ketamine increases neurodegeneration in the developing monkey brain. J Devl Neuroscience. 27: 727-731.

55. Zuo D.Y., Wu Y.L., Yao W.X., Cao Y., Wu C.F. and Tanaka M. (2007): Effect of MK- 801 and ketamine on hydroxyl radical generation in the posterior cingulate and retrosplenial cortex of free-moving mice, as determined by in vivo microdialysis. PharmacolBiochemBehav 86:1-7. 